\title{
Intelligent Algorithm for Maximum Power Tracking of Photovoltaic Energy System
}

\author{
A.H. Mohamed \\ Solid State and Electronic Accelerators Dept., \\ (NCRRT), Atomic Energy Authority.
}

\author{
A.M. Nassar \\ Electronic and Communication Dept., \\ Faculty of Engineering, Cairo University.
}

\begin{abstract}
Tracking the maximum power point (MPP) of a photovoltaic array is an essential operation for any PV system. Thus, changing the environmental conditions causes different maximum power point (MPP) driving for non-uniform power feeding for the load. So, researchers have developed many MPPT algorithms to maximize and stabilize the power derived for the load. But, these algorithms still suffer from some limitations such as high cost, complexity and sometime instability with rapid changes in the environmental conditions. The proposed system introduces integration between the artificial neural networks (ANN) and the fuzzy logic controller (FLC) for achieving MPPT. It can improve the performance of the MPPT algorithm for obtaining a stable maximum power derived for the loads. The proposed MPPT algorithm has been applied for a PV system feeds the power for a camp that exposes the radiation site. The results obtained from the suggested system have proved its significant success for the practical applications.
\end{abstract}

\section{Keywords}

PV Systems, Maximum Power Point Tracking (MPPT), Power Converters, Artificial Neural Networks, Fuzzy Logic Controller.

\section{INTRODUCTION}

With the increase in demand of electric energy nowadays and depleting the traditional resources, renewable energy resources have introduced good solutions for solving the power problems all over the world. From many renewable sources, solar energy has proved to be a good choice for electric power generation, since it can be directly converted into electrical energy by photovoltaic modules. However, photovoltaic (PV) systems preferred for their advantages due to their environmental friendness, and avoiding the high cost and the decreasing amount of the fuels.

On the other hand, the obtained power from the PV modules suffers from instability due to its mainly effecting by the environmental conditions such as solar irradiance and temperature at different time of day. The I-V and P-V output characteristics of the PV cells under the same temperature $\mathrm{T}$ but different solar irradiance levels are varied as shown in Fig. (1). The PV cell exhibits a non-linear output current and voltage relationship. There is a maximum power point (MPP) under any solar irradiance level, where the output power of a $\mathrm{PV}$ cell is maximized.
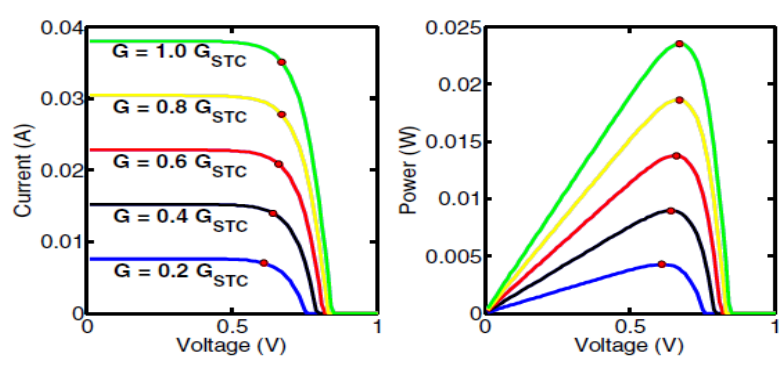

Fig. (1) : The PV cell's I-V and P-V output characteristics under the same temperature $T$ but different solar irradiance levels

Therefore, tracking the maximum power point at these different conditions is important task for ensuring the maximum power and stability of the output power from the PV systems fed for the loads under different environmental conditions.

Researchers have developed many different methods to track the MPP and ensuring the operation of the PV system at its maximum power. The most commonly methods used are: (1) the lookup-table method [1], (2) Perturb \& Observe (P\&O) method [1-3], and (3) incremental conductance method [4].

On the other hand, it is found that, these methods face some drawbacks. Wherever, $\mathrm{P} \& \mathrm{O}$ method may have an oscillation around the MPP at steady state. Besides, the $\mathrm{P} \& \mathrm{O}$ and incremental conductance methods do not perform well in rapidly changing atmospheric conditions, which make them less favorable [1].

More recently, different artificial intelligence (AI) algorithms such as Fuzzy Logic Controllers (FLC) and the Artificial Neural Networks (ANN) have been successfully used for tracking the MPP of the PV systems. FLC algorithms developed are fast convergence and have minimal oscillations around the MPP but their effectiveness depends a lot on the skills of the designer. On the other hand, neural network are recorded over a lengthy period of time, but the MPP can be tracked accurately [5-10].

The proposed system introduces a new intelligent algorithm that can integrate the artificial neural network and fuzzy logic controller approaches to track the MPP of the PV systems. However, the proposed system can have the advantages of both the ANN and FLC to have accurate, stable, higher speed convergence and minimal oscillations around the MPP. So, the proposed algorithm can improve the maximum power point Tracking (MPP) of PV system.

The reminder of the present paper is organized as follows: Section 2 represents the neural network. Section 3, deals with the fuzzy logic controller. Section 4 describes the proposed system. In Section 5, represents the applicability of the 
proposed system and its results, and the conclusions are addressed in Section 6.

\section{ARTIFICIAL NEURAL NETWORK}

Artificial Neural Network (ANN) is made up of interconnecting artificial neurons. A Neural Network is an analog and parallel computing system. It is made up of a number of very simple processing elements that communicate through a rich set of interconnections with variable weights or strength. ANN (subsequently referred to as $\mathrm{NN}$ ) processes information using connectionist approach to computation [11]. It changes its structures based on internal or external information that flows through the network during the learning process. $\mathrm{NN}$ can be used to model complex relationship between input and output or find patterns in data [12]. A simple NN comprises of three layers (Input, Hidden and Output layers) [13] as shown in fig. (2).

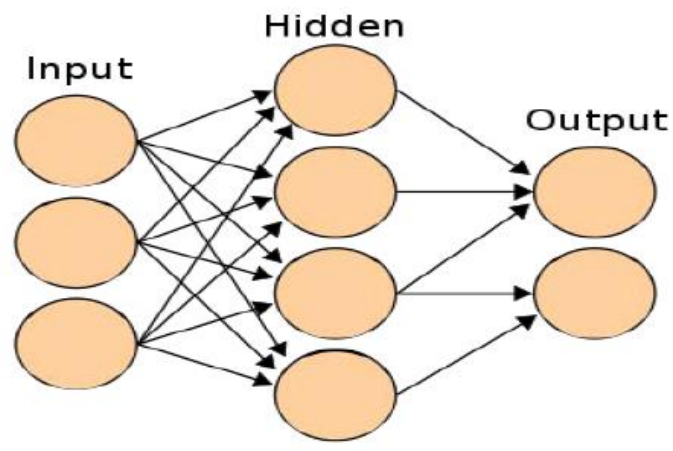

Fig. (2): A simple Neural Network

$\mathrm{NN}$ employs learning paradigm that includes supervised, unsupervised and reinforcement learning. But, NN cannot handle linguistic information and also cannot manage imprecise or vague information [14].

\section{FUZZY LOGIC CONTROLLER}

Fuzzy logic has been introduced to deal with vague, imprecise and uncertain problems. Also, it can mange the non-linear relationship in good manner. Hence, they can find applications in many aspects of real life that exhibit incomplete information.

Fuzzy sets have been used to represent the required variables. A fuzzy set is represented by a membership function defined on the universe of discourse. The membership function maps the elements of the universe onto numerical values in the interval $[0,1]$. A grade of membership in between corresponds to the fuzzy membership to set [15].

However, the fuzzification process decomposes a system input and/or output into one or more fuzzy sets. Many methods are used to reason about the fuzzy systems, the most common ones is the rule base. After fuzzy reasoning we have a linguistic output variable which needs to be translated into a crisp value. The objective is to derive a single crisp numeric value that best represents the inferred fuzzy values of the linguistic output variable. That is called a Defuzzification process [16].

\section{THE PROPOSED SYSTEM}

The main structure of the proposed PV system consists of the PV panel, MPPT controller, and DC-DC converter feeds the power for the load as shown in fig. (3). The MPPT controller uses the intelligent algorithm to achieve the maximum power from PV modules at changing solar irradiance $(G)$ and temperature $(\mathrm{T})$ environmental conditions. The proposed system uses the PV module voltage as the control parameter. The MPPT controller is designed based on this voltage. So, determining reference voltage value (VMPP) that recorded at MPP of the PV panels is the core task.

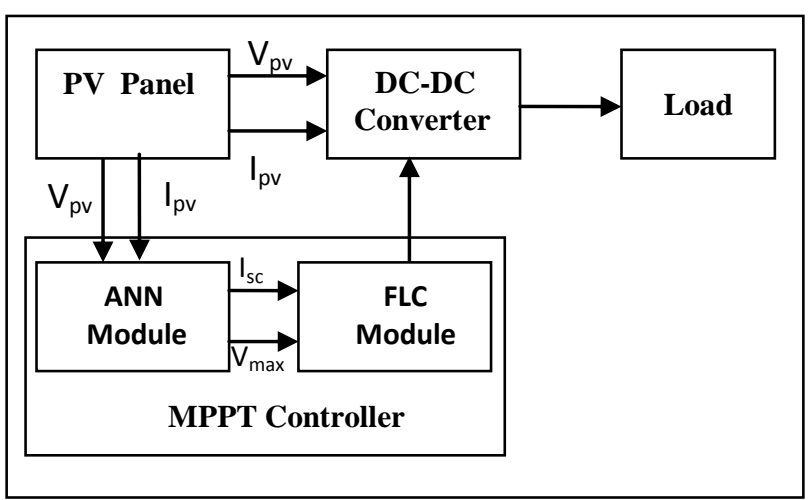

Fig. (3): Block diagram of the proposed PV system

The proposed MPPT algorithm uses two main modules to achieve a stable maximum power feeding for the load. They are: Artificial Neural Network (ANN) Module and Fuzzy Logic Controller (FLC) Module.

Neural network is used to determine the MPP, while fuzzy logic is used to set duty cycle of DC-DC converter. Fuzzy logic controller controls the change appeared in the voltage generated by the MPPT and the PV panel. So, the fuzzy controller adjusts the duty cycle of DC-DC converter that generates an output voltage corresponding to Vmpp.

\subsection{Neural Network Module}

The main goal of the proposed ANN module is achieving the voltage Vmax value.

The current, voltage and power at MPP for a range of irradiance and temperature conditions are recorded. Then, these atmospheric conditions recorded are used as the input data and corresponding MPP values are used as the output data for training the ANN. However, ANN maps the complex nonlinear relations between the inputs and the outputs (VMPP) of the PV systems through training process. The training data is obtained by simulating the PV array in Matlab/Simulink using the parameters of the solar cells given by manufacturer.

The solar panel used in this particular research has the following specifications:

\begin{tabular}{|l|l|}
\hline Model No. & TBP-1235 \\
\hline $\mathrm{I}_{\mathrm{SC}}$ & $2.25 \mathrm{~A}$ \\
\hline $\mathrm{V}_{\mathrm{OC}}$ & $21.2 \mathrm{~V}$ \\
\hline $\mathrm{I}_{\mathrm{MP}}$ & $2.06 \mathrm{~A}$ \\
\hline $\mathrm{V}_{\mathrm{MP}}$ & $17 \mathrm{~V}$ \\
\hline $\mathrm{P}_{\mathrm{MN}}$ & $35 \mathrm{~W}$ \\
\hline $\mathrm{N}_{\mathrm{S}}$ (No. of cells) & 36 \\
\hline Nominal irradiance at $25^{\circ} \mathrm{C}$ & 1000 \\
\hline
\end{tabular}

It is found that, using ANN can avoid some main PV problems such as oscillations around the MPP and trapping in local points [5]. 
Suggested ANN has been implemented by using the feed forward structure. It has 5-hidden layers with 40 neurons as shown in fig. (4). While, simulated 500 experimental measurements are used by the proposed ANN. They have classified as 400 measurements for the training process and 100 ones for the testing. For ensuring a wide range of operating points for the PV system, the used data by the ANN between $30-1000 \mathrm{~W} / \mathrm{m}^{2}$ for irradiance and $10-80{ }^{\circ} \mathrm{C}$ for temperature.

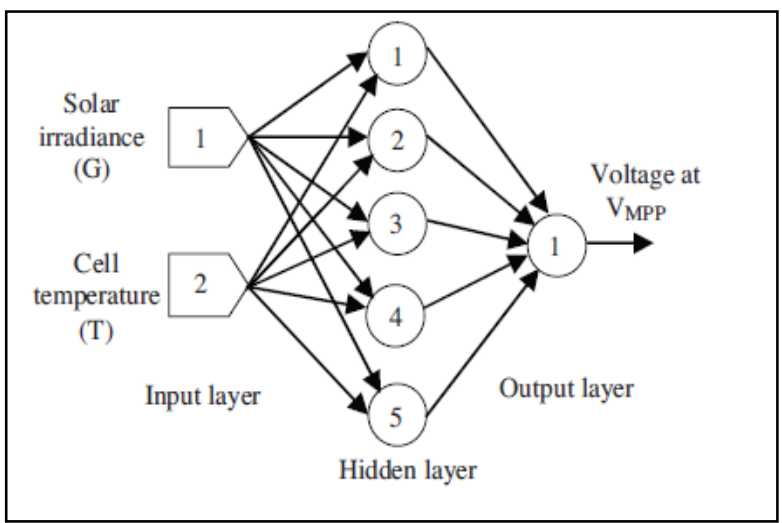

Fig. (4) :The ANN configuration used to determine the reference voltage value at the MPP.

\subsection{Fuzzy Logic Controller (FLC)}

Fuzzy logic controllers (FLC) can control the maximum power point uses DC/DC converter to compensate the output voltage of the solar panel to keep the voltage at the value which maximizes the output power. The inputs for the proposed FLC module are the estimated reference voltage Vmax. by ANN module and the determined its corresponding Isc. FLC controls the duty switching cycle of DC/DC converter. The FLC examines the output PV power at each sample ( $t$ ), and determines the change in power relative to voltage (dp/dv) as shown in fig. (5):

1- If this value is greater than zero the controller changes the duty cycle of the pulse width modulation (PWM) to increase the voltage until the power is maximum or the value $(\mathrm{dp} / \mathrm{dv})=0$.

2- If this value less than zero the controller changes the duty cycle of the PWM to decrease the voltage until the power is maximum value achieved.

The FLC has two inputs:

$\operatorname{Error} E(k)=\frac{P(k)-P(k-1)}{v(k)-V(k-1)}$

Change in Error $C E(\mathrm{k})=E(\mathrm{k})-E(\mathrm{k}-1)$

Where: $P(k)$ is the instant power of the photovoltaic generator. The input error $(\mathrm{k})$ shows if the load operation point at the instant $\mathrm{k}$ is located on the left or on the right of the maximum power point on the PV characteristic, while the input Change_Error expresses the moving direction of this point [17].

However, the converter can match between load voltage and Vmax of PV panels.

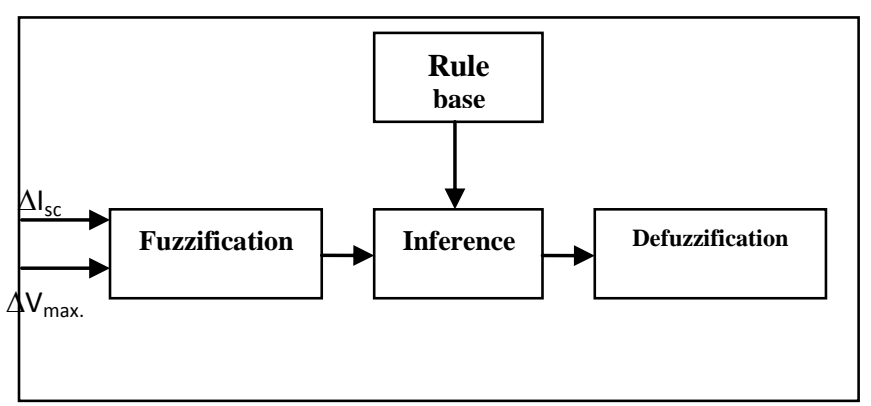

Fig. (5): FLC Controller for the proposed MPPT

Using FLC for PV systems provides some advantages such as:

1- Dealing with a percentage deflection in Vmax to avoid a system fluctuation.

2- The rules discriminate the level of Isc to prevent the oscillation in cloudy time.

On the other hand, it has faced with two main problems, they are:

1- Instability appeared due to great and fast changes in weather condition.

2- Changing the load can cause high changes in output voltages of DC/DC converter [18].

The proposed system has overcome the problems of the traditional FLC for the PV systems as:

1- The neural network module has derived accurate Vmax. used as the input for FLC due to the high accuracy of the ANN behavior. Also, ANN has used a wide board of the environmental conditions to estimate Vmax. So, the proposed system can avoid the instability of the output power of the PV system.

2- Use the rules discriminate the level of Isc to prevent the oscillation in cloudy time.

3- The membership functions (MFs) of FLC are designed to deal with a wide range of resistive load drives the PV panel that can operate in wide interval on I-V curves for different types of loads. This can be achieved by determining the rate and limit of duty cycle at various value of Vin to help on designing the rules and MFs that control the DC/DC converter with battery load.

\section{APPLICABILITY OF THE PROPOSED SYSTEM AND ITS RESULTS}

The proposed system introduces a general purpose algorithm that integrates the neural network and the fuzzy logic controller. It can improve the performance of tracking the maximum power point process for different PV systems. It has been applied to track the maximum power for a PV system used for a camp to expose the radiation sites in the desert as a case of study.

Using P\&O [19], Fuzzy [17] and Neural Network [20] MPPT systems are used to feed the power for the same camp. The proposed system and all the MPPT systems have been modeled and simulated using MATLAB/Simulink.

The obtained results from the three MPPT systems are compared to that one obtained from the proposed system. 
Table (1) represents this comparison of the MPPT systems. While, table (2) represents the comparison between the transit time and the accuracy of the previous MPPT systems, and the proposed one.

From the obtained results, it is found that, the proposed system has proved its significant performance compared with the other systems. The proposed system can increase the accuracy of the power feeding for the PV system and decrease the transit time for the tracking process. However, the proposed system can improve the performance of tracking the maximum power point for the PV systems. Also, the proposed MPPT algorithm improved the transitional state reduced the oscillations in steady state, and speeding up the tracking process.

Table (1): A comparison between the output (voltage, current and power) results obtained from P\&O, fuzzy, neural network and the proposed MPPT systems.

\begin{tabular}{|c|c|c|c|c|c|c|c|c|c|c|c|c|}
\hline \multirow[t]{2}{*}{$\begin{array}{l}\text { Time of } \\
\text { the day }\end{array}$} & \multicolumn{3}{|c|}{ P\&O MPPT System } & \multicolumn{3}{|c|}{$\begin{array}{l}\text { Neural Network MPPT } \\
\text { System }\end{array}$} & \multicolumn{3}{|c|}{ Fuzzy MPPT System } & \multicolumn{3}{|c|}{$\begin{array}{l}\text { Proposed Fuzzy-NN } \\
\text { MPPT System }\end{array}$} \\
\hline & $V(V)$ & $I(A)$ & $P(W)$ & $V(V)$ & $I(A)$ & $P(W)$ & $V(V)$ & $I(A)$ & $P(W)$ & $V(V)$ & $I(A)$ & $P(W)$ \\
\hline 7:00 am & 5.37 & 0.015 & 0.080 & 7.80 & 0.105 & 0.819 & 8.10 & 0.117 & 0.947 & 9.20 & 0.115 & 1.058 \\
\hline 8:00 am & 6.76 & 0.059 & 0.398 & 10.52 & 0.148 & 1.556 & 9.27 & 0.125 & 1.558 & 9.52 & 0.128 & 1.218 \\
\hline 9:00 am & 9.25 & 0.090 & 0.832 & 11.44 & 0.185 & 2.532 & 10.14 & 0.153 & 1.551 & 10.34 & 0.159 & 1.644 \\
\hline 10:00 am & 10.75 & 0.162 & 1.741 & 11.53 & 0.204 & 2.352 & 11.30 & 0.164 & 1.853 & 11.33 & 0.169 & 1.914 \\
\hline 11:00 am & 12.25 & 0.198 & 2.425 & 11.83 & 0.288 & 3.407 & 11.74 & 0.195 & 2.289 & 11.83 & 0.198 & 2.342 \\
\hline 12:00 pm & 12.33 & 0.204 & 2.515 & 11.85 & 0.2885 & 3.418 & 11.76 & 0.2883 & 3.390 & 11.86 & 0.2887 & 3.423 \\
\hline 1:00 pm & 12.58 & 0.237 & 2.981 & 11.88 & 0.2881 & 3.422 & 11.80 & 0.2885 & 3.404 & 11.89 & 0.2886 & 3.431 \\
\hline 2:00 pm & 12.73 & 0.224 & 2.851 & 11.93 & 0.2883 & 3.439 & 11.87 & 0.2887 & 3.426 & 11.91 & 0.2884 & 3.434 \\
\hline 3:00 pm & 12.69 & 0.239 & 3.032 & 11.70 & 0.2885 & 3.375 & 11.72 & 0.2886 & 3.382 & 11.93 & 0.2885 & 3. 441 \\
\hline 4:00 pm & 12.89 & 0.234 & 3.016 & 11.76 & 0.2830 & 3.328 & 11.76 & 0.284 & 3.339 & 11.86 & 0.285 & 3.380 \\
\hline 5:00 pm & 12.74 & 0.171 & 2.178 & 11.92 & 0.2511 & 2.98 & 11.82 & 0.26 & 3.073 & 11.84 & 0.27 & 3.196 \\
\hline 6:00 pm & 12.62 & 0.143 & 1.804 & 12.09 & 0.1872 & 2.260 & 11.92 & 0.197 & 2.348 & 12.01 & 0.189 & 2.269 \\
\hline 7:00 pm & 12.34 & 0.095 & 1.172 & 12.15 & 0.1832 & 2.223 & 12.05 & 0.188 & 2.265 & 12.11 & 0.189 & 2.288 \\
\hline
\end{tabular}

Table (2): A comparison between the transit time and accuracy results obtained from P\&O, fuzzy, neural network and the proposed MPPT systems

\begin{tabular}{|c|c|c|c|c|c|c|c|c|}
\hline \multirow{2}{*}{ Time } & \multicolumn{2}{|c|}{ P\&O System } & \multicolumn{2}{c|}{ Neural Network System } & \multicolumn{2}{c|}{ Fuzzy System } & \multicolumn{2}{c|}{$\begin{array}{c}\text { Proposed Fuzzy-NN } \\
\text { System }\end{array}$} \\
\cline { 2 - 10 } & $\begin{array}{c}\text { Accuracy } \\
\text { \% }\end{array}$ & $\begin{array}{c}\text { Transit } \\
\text { Time (sec.) }\end{array}$ & $\begin{array}{c}\text { Accuracy } \\
\text { \% }\end{array}$ & $\begin{array}{c}\text { Transit } \\
\text { Time (sec.) }\end{array}$ & $\begin{array}{c}\text { Accuracy } \\
\text { \% }\end{array}$ & $\begin{array}{c}\text { Transit } \\
\text { Time (sec.) }\end{array}$ & $\begin{array}{c}\text { Accuracy } \\
\%\end{array}$ & $\begin{array}{c}\text { Transit } \\
\text { Time (sec.) }\end{array}$ \\
\hline Day 1 & 55.3 & 2.7 & 83.1 & 1.52 & 65.2 & 0.84 & 98.5 & 0.42 \\
\hline Day 2 & 50.2 & 2.5 & 83.5 & 1.86 & 63.7 & 0.75 & 98.7 & 0.34 \\
\hline Day 3 & 57.6 & 3.4 & 83.4 & 1.74 & 64.8 & 0.66 & 97.6 & 0.37 \\
\hline Day 4 & 60.1 & 3.3 & 83.9 & 1.43 & 65.4 & 0.78 & 96.9 & 0.32 \\
\hline Day 5 & 53.4 & 2.8 & 83.7 & 1.87 & 55.9 & 0.68 & 97.4 & 0.29 \\
\hline Day 6 & 53.6 & 3.7 & 82.5 & 1.79 & 55.8 & 0.59 & 97.8 & 0.28 \\
\hline Day 7 & 57.8 & 3.8 & 82.1 & 1.76 & 68.2 & 0.61 & 98.3 & 0.26 \\
\hline
\end{tabular}




\section{CONCLUSION}

Recently, MPPT algorithms have great importance for the stabilizing the generated power from the PV systems. Many MPPT algorithms are developed to track the maximum power point. But, they still suffer from some limitations.

This research presents a new intelligent MPPT for the PV system. The proposed system integrates the neural network and the fuzzy logic controller. So, it can integrate the advantages of the accuracy of neural network and the speeding of the fuzzy logic controller. Simulation results of the proposed MPPT can track the MPP faster and more accurate when compared wit the PV system without MPPT, conventional P\&O method and fuzzy MPPT system.

The suggested system can improve the performance of the MPPT of the PV systems due to the following features:

1- The proposed system introduces an integrated system that can have the advantages of both the neural network and the fuzzy logic controller of the PV systems.

2- ANN module can increase the stability and the accuracy of the maximum power point.

3- FLC module can provide a faster convergence and minimal oscillations of the MPPT algorithm.

4- Proposed system can decrease the tracking time and speeding-up its process.

5- Proposed system can be used for the modern complex PV systems that are considered one of the main issues of modern technology.

However, the proposed system can be applied for different types of PV systems. It has been applied for a PV system that feeds the power for a camp exposes the radiation site. Its obtained results are compared with the results for $\mathrm{P} \& \mathrm{O}$, fuzzy MPPT algorithms and using the PV without the MPPT algorithm for the same camp. The achieved results have proved that the proposed MPPT algorithm improved the transitional state reducing the oscillations in steady state, and speeding up the tracking process. Therefore, the proposed MPPT algorithm can be applied for real-time PV systems in successful manner.

\section{REFERENCES}

[1] V. Salas, E. Olias, A. Barrado, A. Lazaro, "Review of the maximum power point tracking algorithms for standalone photovoltaic systems", Solar Energy Materials \& Solar Cells, Vol. 90, pp. 1555-1578, 2011.

[2] C.R. Sullivan, M.J. Powers, "A high-efficiency maximum power point tracker for photovoltaic arrays in a solarpoweredrace vehicle", Proceedings of the IEEE Power Electronics Specialists Conference, pp. 574-580, 2013.

[3] J.A. Gow amd C.D. Manning, "Controller Arrangement For Boost Converter Systems Sourced From Solar Photovoltaic arrays or other maximum power sources", IEE Proceedings - Electric Power Applications, Vol. 147, pp. 15-20, 2010.

[4] K.H. Hussein, I. Muta, T. Hoshino, M. Osakada, "Maximum Photovoltaic Power Yracking: An Algorithm For Rapidly Changing Atmosphere Conditions", Proceedings of the IEE - Generation, Transmission, and Distribution, Vol. 142, pp. 59-64, 2005.

[5] M. Veerachary, T. Senjyu, K. Uezato, "Neural Network based Maximum Power Point Tracking of Coupled-
Inductor Interleaved-boost Converter Supplied PV System using Fuzzy Controller", IEEE Transactions on Industrial Electronics, Vol. 50, pp. 749-758, 2012.

[6] A.A. Kulaksız, "ANN-based control of a PV system with maximum power point tracker and SVM inverter", Ph.D, Dissertation, Sel, cuk University Graduate School of Natural and Applied Sciences, Department of Electrical and Electronics Engineering, Konya, Turkey, 2009.

[7] A.B.G. Bahgat, N.H. Helwa, G.E. Ahmad, E.T. El Shenawy, "Maximum power point tracking controller for PV systems using neural networks", Renewable Energy, Vol. 30, pp. 1257-1268, 2011.

[8] S. T. Hiyama and E.Karatepe, "Investigation of ANN performance for tracking the optimum points of PV module under partially shaded conditions", 2010 Conference Proceedings IPEC, pp. 1186-1191, 2010.

[9] V. Salas, E. Olias, A. Barrado, and A. Lazaro, "Review of the maximum power point tracking algorithms for standalone photovoltaic systems," Sol. Energy Mater. Sol. Cells, Vol. 90, No. 11, pp. 1555-1578, Jul. 2006.

[10] Z.Cheng, Z.Pang, Y.Liu and P.Xue, "An adaptive solar Photovoltaic array reconfiguration methods based on Fuzzy control", in $20108^{\text {th }}$ World Congress on Intelligent Control and Automation (WCICA), pp.176-181, 2010.

[11] F.Z. Brill, D.E. Brown, W.N. Martin, "Fast genetic selection of features for neural network classifiers", IEEE Transactions on Neural Networks, Vol. 3, pp. 324-328, 2012.

[12] H. Patel and V. Agarwal, "Maximum Power Point Tracking Scheme for PV Systems Operating Under Partially Shaded Conditions," IEEE Transactions On Industrial Electronics, Vol. 55, No. 4, pp. 1689-1698, April 2008.

[13] A.A. Kulaksız, R. Akkaya, "Training data optimization for ANNs using genetic algorithms to enhance MPPT efficiency of a stand-alone PV system", International Symposium on Innovations in Intelligent Systems and Applications, pp. 523-527, 2010.

[14] J. Yang, V. Honavar, "Feature subset selection using a genetic algorithm", IEEE Intelligent Systems, Vol. 13, pp. 44-49, 2012.

[15] L. Kottas,S. Boutalis and D. Karlis, "New Maximum Power Point Tracker for PV Arrays Using Fuzzy Controller in Close Cooperation With Fuzzy Cognitive Networks", IEEE Transaction on Energy Conversion, VOL. 21, NO. 3, September 2006, pp. 793-803.

[16] A.M.A. Mahmoud, H.M. Mashaly, S.A. Kandil, H. El Khashab, and M.N.F. Nashed, "Fuzzy Logic Implementation For Photovoltaic Maximum Power Tracking", Proceedings 9th IEEE International Workshop on Robot and Human Interactive Communication, pp. 155 $-160,2000$.

[17] Dipti Bawa, C.Y. Patil, "Fuzzy Control based Solar Tracker using Arduino Uno ", International Journal of Engineering and Innovative Technology (IJEIT) Volume 2, Issue 12, June 2013

[18] T. Esram, P.L. Chapman, "Comparison of Photovoltaic Array Maximum Power Point Tracking Techniques," 
International Journal of Computer Applications (0975 - 8887)

Volume 115 - No. 20, April 2015

IEEE Transactions on Energy Conversion, vol. 22, no. 2, pp. 439-449, June 2007.

[19] M.A. Elgendy, B. Zahawi, and D.J. Atkinson. "Assessment of Perturb and Observe MPPT algorithm implementation techniques for PV pumping applications".
IEEE transactions on sustainable energy, Vol 3, No 1, pp.21-33, 2012.

[20] M.T. Makhloufi, M.S. Khireddine, Y. Abdessemed, A. Boutarfa, " Tracking Power Photovoltaic System using Artificial Neural Network Control Strategy, I.J. Intelligent Systems and Applications, Vol.12, pp. 17-26, 2014. 